\title{
La pintora «Anselma», Alejandrina de Gessler y Shaw (Cádiz, 1831-París, 1907) como escritora: su Autobiografía Recuerdos de Cádiz y Puerto Real (1841-1850)
}

\section{The Painter «Anselma», Alejandrina de Gessler and Shaw (Cádiz, 1831-Paris, 1907) as Writer: his Autobiography Memories of Cádiz and Puerto Real (1841-1850)}

\author{
Laura Triviño Cabrera \\ Universidad de Málaga \\ laura.triviño@uma.es
}

\section{RESUMEN}

Este artículo persigue exponer las dificultades que tenemos a la hora de analizar la contribución literaria de una de las pintoras más célebres y reconocidas durante el siglo XIX tanto en España como en Francia: Alejandrina de Gessler y Shaw, conocida como «Anselma» en el mundo artístico. Bajo el título Recuerdos de Cádiz y Puerto Real (1841-1850), Fulana de Tal, un nuevo pseudónimo que la pintora inventó para su faceta como escritora; expone, con una similar estructura a la de los relatos de viajes, la vida cotidiana de su Cádiz natal. El estudio de su vida y su trayectoria artística, nos permite fijar nuevas hipótesis que nos ayuden a comprender cuáles fueron los motivos que llevaron a la pintora a redactar una autobiografía; así como las peculiaridades de dichas memorias que introducen aspectos novedosos como la ruptura con el adultocentrismo, el sexismo y el etnocentrismo.

Palabras Clave: Autobiografía; relatos de viajes; pintora; vida cotidiana; Anselma; Fulana de Tal; Cádiz.

\section{ABSTRACT}

This article is aimed at exposing the difficulties of analysing the literary contribution of one of the most famous and recognized painters in the nineteenth century in Spain and France: Alejandrina de Gessler and Shaw, known as «Anselma» in the art world. Fulana de Tal was a new pseudonyme invented by the artist with which Alejandrina de Gessler signed Memories of Cadiz and Puerto Real (1841-1850). In this book, Fulana de Tal wrote, as a travelogue, the daily life of his native Cadiz. The study of his life and career will allow setting new hypotheses that could help to understand why the artist wrote his autobiography; as well as the peculiarities of these memories that introduce new aspects as the rupture with the adultcentrism, sexism and ethnocentrism. Cadiz.

Key words: Autobiography; Travel Stories; Painter; Daily Life; Anselma; Fulana de Tal; 


\section{INTRODUCCIÓN}

La pintora española Alejandrina de Gessler y Shaw era hija del cónsul ruso Alejandro de Gessler y de María Aurora Shaw, dama malagueña de familia de comerciantes de ascendencia escocesa. Para su faceta, tanto de pintora como de escritora, empleó dos pseudónimos distintos. En primer lugar, «Anselma», la artista española que desarrolló su exitosa carrera artística en los Salones Oficiales de París bajo las enseñanzas de su maestro Charles Chaplin. En segundo lugar, «Fulana de Tal», la escritora gaditana que presenta una autobiografía con estructura de relato de viajes titulada Recuerdos de Cádiz y Puerto Real 1841-1850 (1898), donde recopila los episodios y los aspectos más significativos de su vida en Cádiz, en su etapa infantil y adolescente.

Se trata de una obra finalizada en la capital francesa el 5 de diciembre de 1898; y publicada en 1899 por la Librería de los Hermanos Garnier en París. Consta de 110 páginas y se divide en siete capítulos en los que se explican numerosas costumbres y tradiciones gaditanas de las que la pintora era partícipe y a las que asistía asiduamente.

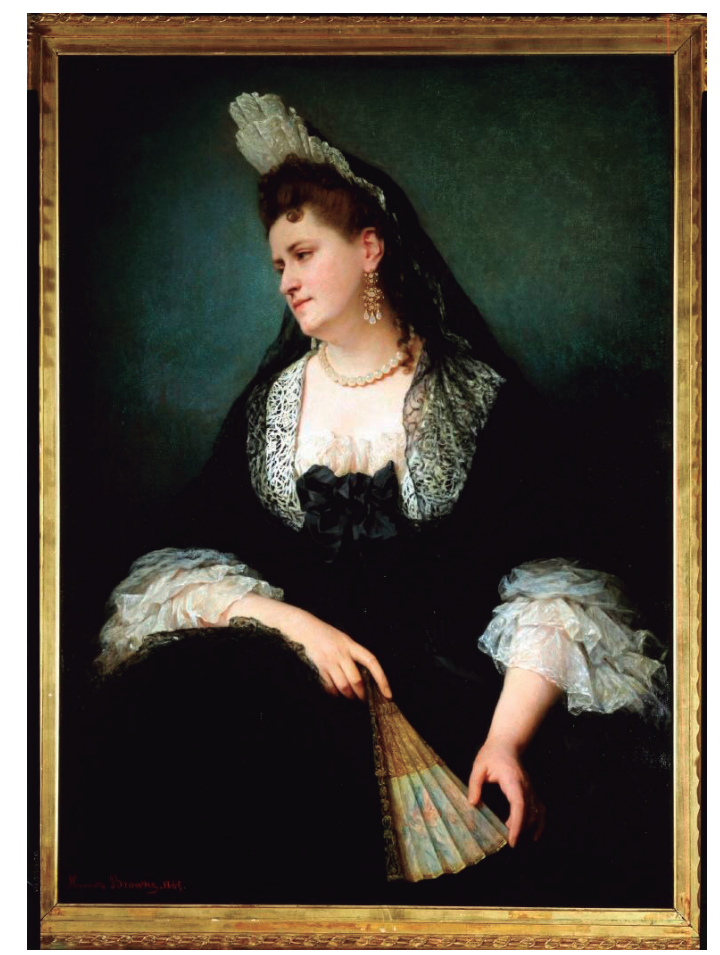

Henriette Browne: Retrato de Madame Anselma, 1865. Óleo sobre lienzo, $129 \times 95 \mathrm{~cm}$. Museo de la Real Academia de Bellas Artes de San Fernando de Madrid. 


\section{LA PROBLEMÁTICA EN TORNO AL HALLAZGO DE AUTOBIOGRAFÍAS FEMENINAS}

Si el género autobiográfico ${ }^{1}$ se alzaba como una forma mediante la que el escritor, el político, el pintor... se convirtiera en sujeto protagonista ante el lector; era comprensible que pocas mujeres, dada su situación bajo el patriarcado, estuvieran dispuestas a escribir sus memorias, a ejercer como sujetos. Asimismo, cabe resaltar que a finales del siglo XIX se producirá un verdadero auge de la autobiografía, fundamentalmente aquélla que narra «memorias políticas, militares o diplomáticas, obras extensas y casi siempre minuciosas que desgranan toda una carrera pública o una parte de ella, a modo de testimonio histórico y casi siempre también de defensa personal» (Durán López, 2001: 45).

Normalmente se había apuntado que la autobiografía había sido poco utilizada por las mujeres en España y existía un desconocimiento en torno a posibles autobiografías de artistas. El caso de Alejandrina de Gessler y Shaw es muy significativo dado que se trata de una pintora, que en ningún momento, habla de arte o de posibles influencias artísticas, pese a que, durante su infancia viviría de cerca cómo su padre atesoraba una colección de pintura española. Ella misma puntualizará su nueva faceta ante sus lectores de la siguiente manera:

sean indulgentes para tanta cosa como lo necesitaré, principiando por mi muy incorrecto andaluz y mi completa inexperiencia como escritora, para pensar sólo en acoger con paciencia y amenidad estos Recuerdos que les ofrece la fiel amiga de antaño (Fulana de Tal, 1898: VI).

Asimismo, cabría preguntarse si la protagonista era De Gessler y Shaw o Cádiz. Recordemos cómo Susan Kirkpatrick plantea la autobiografía como un proceso en el que la escritora escribe el yo para el otro y para ello, se basa en la autobiografía de Gertrudis Gómez de Avellaneda. En 1839, Gómez de Avellaneda escribe un informe sobre su vida al hombre del que se había enamorado, Ignacio Cepeda. De manera que la autobiografía se erige como un «acto de seducción» donde la escritora deja de ser la protagonista (Kirkpatrick, 1991: 133-134). Con respecto a la pintora, su autobiografía habría antepuesto la descripción de la ciudad; quedando configurada como una especie de relato de viajes sobre Cádiz y Puerto Real.

DIFICULTADES PARA RELACIONAR A LA PINTORA ANSELMA CON LA ESCRITORA «FULANA DE TAL»

Hasta el siglo XXI, era habitual, entre los autores, que los Recuerdos de

\footnotetext{
${ }^{1}$ No obstante, según Fernando Durán (1994: 459), «a una mujer le cabe el honor de haber escrito lo que vivió entre los siglos XIV y XV».
} 
Cádiz y Puerto Real (1841-1851), firmados bajo el nombre de Fulana de Tal, no fuesen relacionados con la pintora Anselma².

En una copia de dicha obra, ubicada en la Biblioteca de Andalucía en Granada, se observará una dedicatoria a su sobrina Susana y firmada por la artista, «A. Lacroix ${ }^{3}$. París, 3 Sept 1900».
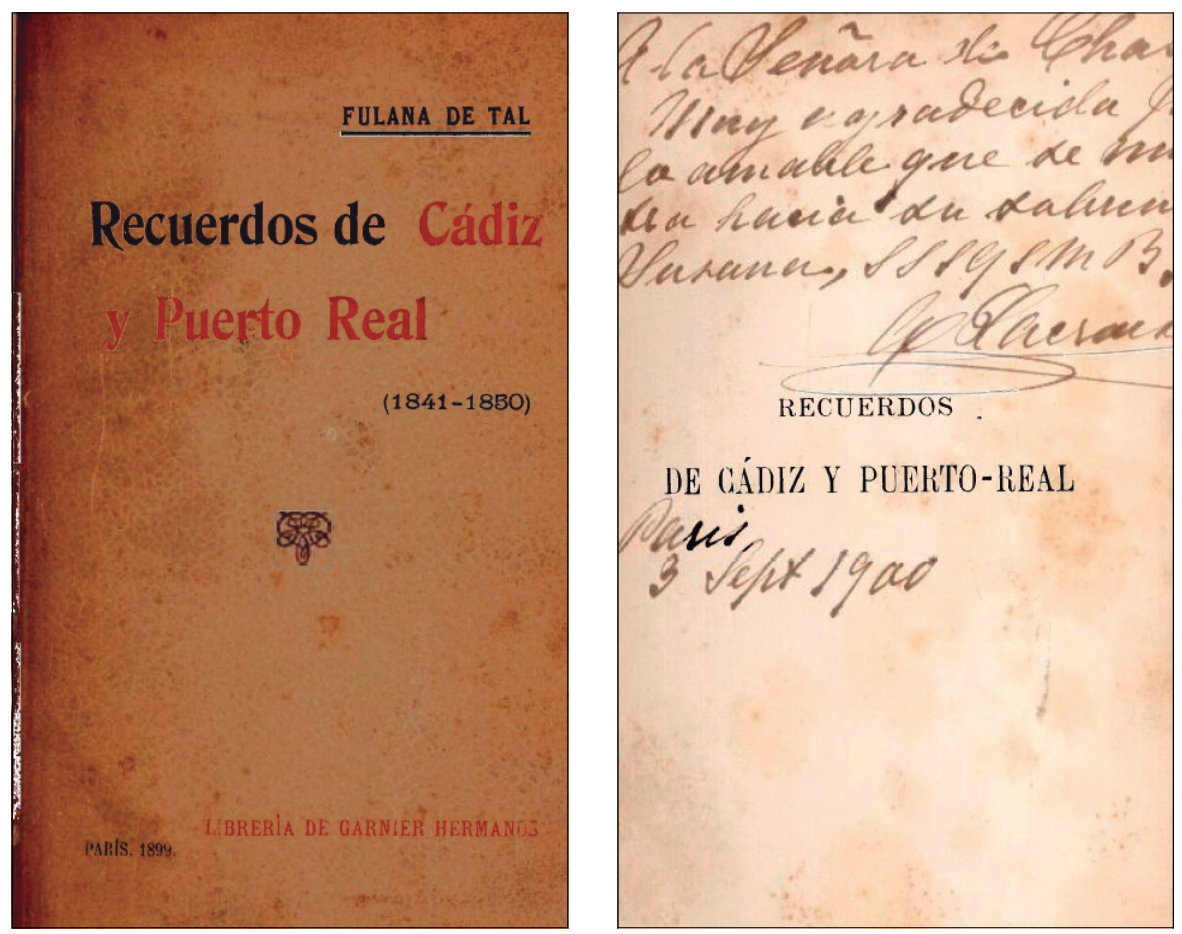

Portada de los Recuerdos de Cádiz y Puerto Real 1841-1850 (1899).

${ }^{2}$ Solo Ramón Solís reconoce a la pintora como autora de los Recuerdos de Cádiz y Puerto Real («Geisler Lecroix (Alejandrina)», véase Solís [2000: 528] y el artículo del mismo autor, «Alejandrina Gessler o Anselma Lacroix», diario ABC. 13 de enero de 1962, p. 17). Obras como Cádiz en el siglo XIX. De ciudad soberana a capital de provincia de Alberto Ramos Santana (1992: 71) o Gran Teatro Falla de Juan Ramón Cirici y Alberto Ramos (1995: 32) no aclaran que se trataba del pseudónimo de la pintora Anselma. Y basándose en el libro de Ramos Santana, en un artículo de 2002 sobre «Representaciones de Zarzuela en el Puerto a finales del siglo XIX» se dirá: «conclusión que obtiene el autor del testimonio, entre otros, de una anónima señora que bajo el pseudónimo de Fulana de Tal escribió un libro titulado Recuerdos de Cádiz y Puerto Real» (vid. García de las Mozas, Ascensión y Becerra Fabra, Ana, «Representaciones de Zarzuela en el Puerto a finales del siglo XIX», Revista de Historia de El Puerto. 29, 2002, p. 49). 
Pensamos que la presencia de su familia materna los Fernández-Shaw en la vida de Alejandrina de Gessler y Shaw pudo ser trascendental para conservar su testimonio, concretamente sus Recuerdos de Cádiz y Puerto Real que se habrían convertido en unos escritos destinados principalmente a su familia y a sus amistades gaditanas. Aunque no tenemos datos más fiables sobre esta hipótesis, sí que se puede ver el empeño de la pintora por recordar su querida patria mediante unas cartas $^{4}$ dirigidas a sus familiares con las que se topa el hijo de Carlos Fernández Shaw, Guillermo Fernández-Shaw ${ }^{5}$ :

El manojo de cartas ya amarillentas reposaba en el fondo de un arca, sujeto por una cinta azul medio desteñida. El deseo de encontrar unos documentos familiares me hizo tropezar con estas cartas, escritas con letra firme y angulosa y firmadas con un nombre desconocido: «Anselma». ¿Quién era esta «Anselma» que en el año 1899 escribía desde París largas epístolas en las que se recreaba contando episodios de su infancia? «Anselma» fue el seudónimo de una distinguida dama gaditana que casó con un acaudalado francés, M. Lacroix, y dio suelta en París a una de sus grandes aficiones de artista: la pintura. Muros y techos de varios palacios parisienses conservan aún las bellas composiciones pictóricas de Alejandrina Guesler; pero ésta, en su ancianidad, rodeada de afectos y de comodidades, no sentía la vanidad de la artista triunfadora y, en cambio, experimentaba con vehemencia la precisión de evocar los recuerdos de su niñez; de la niñez transcurrida, al mediar el siglo XIX, entre Cádiz y Puerto Real, que es tanto como decir entre una casa de mármoles blancos y cortinas de encajes y una finca de campo de viejas costumbres y ricos muebles de caoba. En las cartas de «Anselma» a una antigua compañera de juegos va recordándole diversos momentos de sus vidas en los años de 1849 a 1856 . Con sencillez — que es su principal encanto- desfilan por las páginas amarillentas tipos y costumbres de Cádiz, de un encanto sugestivo; fiestas populares y otras «antiguachas», como ellas las denomina, que se nos presentan como estampas animadas representativas de una época ${ }^{6}$.

A partir de la publicación de Veinticinco escritores gaditanos raros y olvidados (Romero y Durán, 2001), donde la profesora Marisa de las Cuevas dedica un capítulo a «una pintora metida a escritora al final de su vida», se empieza a vincular el pseudónimo «Fulana de Tal» con la artista gaditana ${ }^{7}$.

${ }^{3}$ Lacroix era el apellido de su marido, el diplomático francés Charles Lacroix.

${ }^{4}$ Estas «cartas amarillentas» a las que se refiere Guillermo Fernández-Shaw, serían los Recuerdos de Cádiz y Puerto Real; y la letra angulosa, es la que aparece en la primera página; una dedicatoria de la pintora a su sobrina Susana.

${ }^{5}$ Para no perder la ascendencia Shaw que les venía por línea materna - y que como podemos ver en el Apéndice, en el capítulo dedicado a la Genealogía, procede de un largo linaje de ascendencia escocesa - se unieron ambos apellidos conformando uno solo: Fernández-Shaw.

${ }^{6}$ Archivo Histórico Municipal de Cádiz. Caja. Fernández-Shaw, Guillermo (1955), «Unas Navidades Gaditanas de hace un siglo. Canciones de zagales y señores ante el portal de Belén», El Correo de Andalucía. 13 de mayo de 1955, p. 11.

${ }^{7}$ No obstante, debemos decir que se empieza a vincular ambos nombres en estudios históricos y artísticos sobre la ciudad Cádiz. Ya en 1987, Estrella de Diego había comentado la faceta literaria de Anselma como «gran aficionada a las letras, publicó sus Recuerdos de Cádiz» (2009: 378). 
No obstante, los Recuerdos de Cádiz y Puerto Real presenta dificultades a la hora de su interpretación porque, aunque pudiera parecer que las autobiografías son fáciles de seguir por su escritura sencilla y directa; la autobiografía, como señala Fernando Durán, «ofrece una aplicación muy retorcida de las ideas acerca de la identidad individual, de la historia, de la representación literaria de la realidad, del papel del individuo en su entorno social, de la fiabilidad de la memoria, etc.» (Durán López, 2002: 187).

Son muchos los interrogantes que presenta esta autobiografía. Para empezar, la pintora evita por todos los medios comentar cualquier aspecto sobre su trayectoria artística; de ahí, las dificultades para saber que Fulana de Tal era Anselma, la pintora; Alejandrina de Gessler y Shaw.

\section{LA RUPTURA DE LA AUTOBIOGRAFÍA DE ALEJANDRINA DE GESSLER Y SHAW CON EL ADULTOCENTRISMO, SEXISMO Y ETNOCENTRISMO}

Por tanto, la pintora, evitando su identificación, se centra en su etapa infantil $^{8}$ y adolescente, justamente los períodos de la vida humana que habían pasado más desapercibidos. En relación a esta consideración, conviene señalar las palabras de Manuel José Quintana quien, en su Memoria del Cádiz de las Cortes, expondrá:

[...] los recuerdos de infancia están fuera de lugar y no tienen razón alguna de ser, porque la concepción de la identidad personal que desarrollan se fabrica únicamente desde la perspectiva del adulto, y más en concreto del adulto sabio que se legitima por su excelencia intelectual, luego lo que nos podría llamar la atención es que apareciese en su relato la memoria íntima de la niñez, eso sería lo asombroso y lo que merecería exégesis por nuestra parte. Lo cierto es que ninguno de los escritores que practican esa forma de autobiografía literaria habla de su infancia, a no ser para subrayar su precocidad en el acceso a la sabiduría o algunas etapas de sus estudios primerizos [...] (Durán López, 2002: 173).

Los recientes estudios antropológicos han demostrado que estas consideraciones no son más que fruto de un triple eje: etnocentrismo, sexismo y adultocentrismo. La infancia ha sido considerada una fase transitoria y simple de la persona pero contrariamente; bebés, niños, adolescentes o jóvenes aporta una información esencial sobre la evolución demográfica, social y ecológica (Ramírez Goicoechea, 2009: 63-64). No obstante, debemos señalar que el menosprecio hacia la infancia no siempre ha sido así. Si Manuel José Quintana, en

${ }^{8}$ Sobre la etapa infantil, Pardo Bazán escribirá: «Actualmente se piensa mucho en complacer, divertir y alegrar a los niños: nuestro siglo consagra a esos capullos de humanidad atención preferentísima y culto idolátrico; se les mima bastante, y se encuentra placer en despertar sus tiernas imaginaciones a la noción de la vida y del arte, y en allanarles el camino de sus primeras etapas». Vid. Pardo Bazán, Emilia, «Carta X. Gente Menuda. París, Junio 29» (1899: 147). 
el siglo XIX, hablaba de que los recuerdos de infancia estaban fuera de lugar; un siglo antes, Jean-Jacques Rousseau concedió un papel trascendental a la infancia: «Hay quien se queja del estado de la infancia, y no se da cuenta de que la raza humana habría perecido si el hombre no hubiese empezado siendo un niño» (Rousseau, 2002: 26).

Siguiendo el planteamiento ilustrado de Rousseau en torno a la infancia, la propia pintora Marie Elisabeth Vigée Lebrun (1755-1842) inicia su autobiografía - una de las pocas autobiografías de mujeres artistas de las que tenemos constancia-Memoirs of Madame Vigée Lebrun, con la siguiente declaración en el primer capítulo dedicado a su infancia y juventud: «I will begin by speaking of mi childhood, which is the symbol, so to say, of my whole life, since my love for painting declared itself in my earliest youth» (Vigée-Lebrun, 1903: 6).

Por tanto, como hemos señalado, la pintora estaría en la línea del pensamiento ilustrado y su percepción sobre la infancia. De hecho, Rousseau plasmará sus recuerdos de infancia en Confesiones, donde relata la vida con su familia; e incluso, llegará a incorporar la letra de las melodías que de niño escuchaba cantar a su tía Susana; como también hará la propia pintora con los villancicos 9 .

Recuerdo algunos de esos populares villancicos de disparatada ingenuidad que con obstinado empeño se han grabada en la mente, y no tengo más remedio para desahogar el almacén de los recuerdos que concederme el inocente placer de escribir algunos de los que con más tenacidad se han metido en mi memoria con sus incorrecciones y todo. Esto, desde luego, será más bien cargante que otra cosa para los que viven en nuestra tierra, visto que estos villancicos se cantan aún en toda España; pero a mí como expatriada me interesa el anotarlos, no sea cosa que se me escapen de la memoria y no los pueda volver a pescar. Séame perdonada esta majadería, si majadería fuese. Además, si estas paginillas cayesen en manos de algún extranjero pudieran tener interés para él no como no iniciado. Salten, pues, por encima los que las conocen ya, y vamos a mis coplas, algunas de cuyas entonaciones doy puestas en música por su típica y curiosa melodía (Fulana de Tal, 1899: 37-38).

De manera que las emociones y las impresiones de la pintora durante su infancia serían proyectadas tanto en la obra de arte, como en sus escritos recogidos en Recuerdos de Cádiz y Puerto Real.

${ }^{9}$ «Seguro estoy de que a ella [su tía Susana] debo el gusto, o mejor, la pasión por la música, que no se desarrolló en mí basta mucho tiempo después. [...]. Tanto me cautivaban sus canciones, que no sólo he conservado en la memoria muchas de ellas sino que aún hoy día, que casi la he perdido, algunas que tenía completamente olvidadas desde la infancia reaparecen a medida que voy envejeciendo, con un encanto que trataría en vano de explicar. ¿Quién diría que yo, viejo caduco, roído por las preocupaciones y los sufrimientos, me he sorprendido algunas veces llorando como un chiquillo al murmurar aquellos cantos con voz ya trémula y cascada? La melodía de uno de ellos, sobre todo, se ha reproducido en mi memoria, habiendo sido vanos todos mis esfuerzos para recordar la mitad de la letra, aunque hallo confusamente las rimas». Rousseau, Jean-Jacques: Confesiones (1765-1770), Edición Electrónica de Escuela de Filosofía Universidad ARCIS, p. 5, http://www.seminariodefilosofiadelderecho.com/biblioteca/ r/confesionesrousseau.pdf. 
Por otro lado, dirigir la mirada hacia la infancia, era uno de los rasgos del movimiento romántico que iniciará

una revalorización de la infancia, la mujer, las gentes del pueblo; todos ellos en contacto directo con la naturaleza lo que les convertía en seres incontaminados e ingenuos. Se producirá, en general, una revalorización de la Historia y, en particular, de la cultura de cada pueblo que conlleva la búsqueda de la propia identidad en las distintas épocas pasadas y presentes (Seguí, 2003: 267).

Aspectos que podemos contemplar en la pintura costumbrista de Anselma, concretamente en La Adoración de la Cruz (1869), que llegaría a ser premiada con la Medalla de Oro en la Exposición Regional celebrada en Cádiz.

En esa mirada hacia la infancia, quisiéramos resaltar dos episodios que la pintora vivió con especial ilusión de niña: poner El Nacimiento y asistir al teatro de títeres La Tía Norica.

El primero de ellos está vinculada a la celebración de tradiciones religiosas gaditanas que la pintora organizaba junto a sus hermanas y hermanos, supervisada por las que ella denominaba cariñosamente «amas secas»o «criadas» que también formaban parte de su «familia tradicional» ${ }^{10}$, quiénes se encargaban de organizar las diferentes festividades que se iban dando a lo largo de todo el año en la casa. Una de ellas era el Nacimiento:

Hablando de Pascuas, cuando se iba acercando la de Navidad, la familia menuda, es decir, nosotros los niños, nos empezábamos a agitar sobremanera, pensando ya en poner el nacimiento. Nuestra buena María era la gran sacerdotisa que presidía esta importante maniobra, y si bien no cortaba como Norma con dorada hoz el gui (nuestro muérdago) de las Druídas, compraba con buenas pesetas la yerba para figurar la improbable vegetación del Nacimiento. [...]. Todo esto se encendía a las horas en que se reunía la familia y los amigos de ésta, sobre todo, las amigas de nuestras criadas, que venían a cantar. Entonces era cuando para celebrar al Niño soltábanse las coplas, ¡y qué coplas tan particulares! Y sonaban panderetas y zambombas. A pesar de los muchos años que hace ya que en estos coros cantaba yo también ¡y qué volando han pasado estos años! (Fulana de Tal, 1899: 35).

El segundo de ellos era la ilusión infantil por escuchar las historietas de la Tía Norica y su sobrino:

¿Y dónde me dejáis, si no siguiera enrayando (aunque tal vez no se desconozca mucho), lo que tuviera que extenderme, si describiese prolijamente los lances del teatro de muñecos (la alegría de los niños) de la entonces tan famosa Tía Norica? [...] esta Tía Norica era una desdichada viejecita que tenía, por desgracia, un nieto muy mala cabeza, llamado Batillo [...]. Originales hasta no más eran los muñecos, pero lo que no hubiera con qué pagar, fuera poder reproducir in extenso los coloquios que entre ellos pasaban, con detalles tan de confianza y con una despreocupación tan ingenuamente indecorosa, para el papel que representaban, que a la gente grande no le era siempre fácil el mantenerse seria (Fulana de Tal, 1899: 105-108).

\footnotetext{
${ }^{10}$ Fulana de Tal hablaba de su «familia tradicional» que en 1898 se estaba perdiendo, compuesta por su padre, madre, abuela materna, sus hermanos y sus hermanas, y sus criadas.
} 
En torno al segundo concepto «sexismo», en lo que se refiere al siglo XIX, el protagonista principal en la autobiografía debía ser un hombre adulto; pero Alejandrina de Gessler y Shaw rompe con esta estructura. Ahora, la autobiografía se centraba en una niña y en una mujer joven:

Hay horas muy tristes en la vida, y en algunas de estas horas de las que meten el corazón en un puño, me vino la idea, para no dejarme ir sin riendas a mis penas, de esforzarme, echando la vista atrás hacia los felices años de mi niñez y de mi juventud, a poner por escrito lo que a la memoria me viniese de aquellos tan pasados tiempos (Fulana de Tal, 1899: V).

Por último, debemos analizar la cuestión en torno al «etnocentrismo» en su autobiografía. Aunque no predominan, se aprecian ciertas anécdotas que vinculan Andalucía con Marruecos; la pintora Anselma, a través de sus viajes, adoptó una postura más abierta en la aceptación de otras culturas que se ve reflejada tanto en su obra literaria como artística. Con respecto a este último punto, cabe detenerse puesto que la visión de Oriente es la única temática que aparece tanto en su autobiografía como en algunas de sus cuadros. Pero lo más destacable es cómo Anselma proporciona una imagen más cercana a las mujeres africanas, más proclive a encontrar similitudes que diferencias. Al igual que existe un vínculo común dado que comparten el mismo sexo, también la pintora conocerá lo que es ser el «otro» y el «yo» al mismo tiempo. La procedencia andaluza de Anselma le permitía sentir lazos más próximos con Oriente, así lo expresa cuando comente las semejanzas entre el pueblo gaditano y el marroquí:

En Puerto Real se pasaba mucho tiempo en la calle, sin ponerse nada encima, ni en la cabeza, a menos que no fueran flores; los sirvientes de casa, ya aseados, no dejaban de adornar su cabello con ellas, y, sobre todo, con sartas de suspiros que nosotros los niños les preparábamos a menudo. Esta moda debía seguramente tener origen árabe, como tantas otras en Andalucía, pues en un viaje que hice a Tánger años después, muchas jóvenes que vi un día de gran función, tenían sartas análogas de hojas de azahar y varias otras florecitas (Fulana de Tal, 1899: 20).

$\mathrm{Y}$ es en este fragmento donde se atisba la búsqueda de lo árabe en Andalucía, tal y como Anselma había podido ver en los bailes de Puerto Real.

Esta aproximación también se observa en la obra de su amiga y pintora que le aconsejó iniciar su carrera artística, Henriette Browne (pseudónimo de Sophie Bouteiller). Anselma, siguiendo los pasos de su amiga, quien cosechó un gran éxito por su obra orientalista Interior de un harem (1861), escena que pudo contemplar in situ en Turquía; reproducirá un acontecimiento que presenció en Marruecos, Nacimiento en Tánger (1872). La oportunidad que tuvieron ambas pintoras de poder contemplar dichas culturas se presentó, por la profesión de sus respectivos maridos como diplomáticos.

De manera que Anselma como «yo» persigue encontrar semejanzas con el «otro»; aunque al mismo tiempo, se percata de que ella es tratada como «otro» 
con cierto recelo por el grupo de mujeres, que finalmente terminan aceptando su presencia allí:

pero a mí, como cristiana, me miraban las árabes con desconfianza; sin embargo, después de mucha vacilación, me llevaron hasta la alcoba donde se hallaba la madre del recién nacido en aparatosa cama con su niño en los brazos; y aunque me hallaba sobrecogida de verme rodeada de tanta figura de puras árabes, gozaba plenamente de mi suerte de haber logrado admirar escena tan interesante (C.M., 1908: 10).

En este caso, podemos ver un recuerdo que podría ser contemplado como relato de viaje y que como, expone Patricia Almarcegui, estaríamos ante el siguiente sentimiento:

Para aproximarse al Otro es necesario percibir lo mismo que él percibió. Tener la ilusión de que se siente lo mismo que él, de allí la carga afectiva con la que y de la que se van llenando los lugares. En ellos, el viajero establece un lazo afectivo difuso como concepto, pero vivido y concreto como experiencia personal (Almarcegui, 2011: 284).

\section{TRASLADAR LA ESTRUCTURA DE LOS RELATOS DE VIAJES A LA AUTOBIOGRAFÍA}

Y precisamente, relacionado con este último punto y observando la estructura de sus Recuerdos. ¿Podría Alejandrina de Gessler y Shaw haber tomar como modelo algún relato de viajes? A lo largo del siglo XIX, son abundantes los relatos de viajes de artistas, escritores y políticos que escriben sobre Cádiz. Tenemos el caso de Théophile Gautier y su Voyage en Espagne o Eugène Delacroix y su Viaje a Marruecos y Andalucía. Sin embargo, será Viaje por España de Gustavo Doré y Charles Davillier, el que más se aproxima a la manera en la que la pintora concibe su descripción de Cádiz (Doré y Davillier, 1982). Al igual que Doré y Davillier, la pintora incorpora partituras (Fulana de Tal, 1899: 346-347) y poemillas populares ${ }^{11}$. Por otro lado, la división de sus capítulos se hace en el índice y durante el relato no existen los apartados dentro de los capítulos. Fulana de Tal, como Doré y Davillier, habla de las azoteas, de las mantillas, las confiterías, los bailes de Cádiz o las gaditanas. Puede que la pintora, hubiese leído este Viaje por España publicado por entregas en la prensa francesa de 1862 a 1873, y le hubiese servido de inspiración. Sin embargo, existe una gran diferencia entre ambos autores. Si Nieves Soriano afirma que la creación de un relato de viajes implica la posesión de una visión de alteridad (Soriano, 2009: 112), en el caso de Alejandrina de Gessler y Shaw no existe, dado que ella se sitúa como gaditana que cuenta las costumbres de la ciudad que le vio nacer.

\footnotetext{
${ }^{11}$ Anselma habla de Periquillo «el Aguador»; mientras que Doré menciona a Curriyo «el Marinero».
} 
Nos gustaría apuntar cómo la pintora sabe que con esta obra, inicia su faceta como escritora y la finalidad que quiere perseguir: recordar su vida en Cádiz.

\begin{abstract}
Verán estos amigos y compatriotas, que a la que nació allí en el Cádiz de nuestra España no se le ha olvidado nada de lo de por allá; y si el haber tratado de lo que pueda parecer pamplinas les hiciese temer que me haya acometido ya algo la chochera, que se acuerden que (años más años menos) somos contemporáneos y al leerme, sean indulgentes para tanta cosa como lo necesitaré, principiando por mi muy incorrecto andaluz y mi completa inexperiencia como escritora, para pensar sólo en acoger con paciencia y amenidad estos Recuerdos que les ofrece la fiel amiga de antaño (Fulana de Tal, 1899: VI).
\end{abstract}

Se trata de unos escritos que constituyen el documento base para conocer el interés por cultivar la pintura costumbrista y un testimonio único para aproximarnos a la vida cotidiana del Cádiz de la primera mitad del siglo XIX. Obra singular y que, a juicio de Ramón Solís,

es por sí sólo merecedor de un buen prestigio literario. En un género tan poco frecuente en España como es el de las memorias logra en un centenar de páginas una de las mejores descripciones de las costumbres y el ambiente de su época. [...]. Quizás uno de los mayores encantos de sus Recuerdos de Cádiz y Puerto Real está en la sencillez y gracia de decir las cosas en medio de una época de lirismo exuberante y de párrafos engolados y farragosos. La otra gran cualidad de esta obra es la sinceridad con que recoge lo cotidiano. No sé por qué, los cultivadores en España de este género literario - por otra parte son muy escasos- piensan que es necesario haber vivido grandes aventuras o intervenido de manera muy señalada en la vida pública. La mayor parte de nuestros escritores que han escrito recuerdos o memorias lo han hecho o para disculparse o para dar constancia de su actuación política o social ${ }^{12}$.

Por otra parte, resulta curioso que, a la edad de 68 años, Alejandrina de Gessler y Shaw decidiera publicar unos escritos de infancia y juventud en Cádiz, cuando la pintora por su trayectoria personal y artística, habría tenido la oportunidad de publicar episodios interesantísimos dado los viajes que hizo, las personalidades que conoció y lo más importante de todo, su experiencia y sus reconocimientos como pintora. De hecho, la pintora desde que era muy pequeña, tenía la costumbre de plasmar todas sus anécdotas y todos los episodios más relevantes de su vida, incluyendo los procedimientos que debía desarrollar para ejecutar sus obras, en un diario. Así pues, lo más lógico hubiese sido publicar estos aspectos, como haría la pintora francesa Elisabeth Vigée Lebrun, relatando sus viajes, vivencias personales y carrera artística ${ }^{13}$ o la pintora rusa Marie Bashkirtseff (Gavrontsy, 1860-París, 1884) —discípu-

\footnotetext{
${ }^{12}$ Solís, Ramón... Vid. nota 3.

${ }^{13}$ La pintora escribirá sobre los lugares que visitó, dedicándoles a cada uno de ellos un capítulo: Nápoles, Turín y Viena, San Petersburgo, Moscú o Inglaterra. Vid. Vigée Lebrun (1903).
} 
la del pintor Bastien-Lepage y que expuso en los salones oficiales de Parísen su diario, finalizado días antes de su fallecimiento, donde narra su viaje por España, deteniéndose principalmente en aquellos aspectos relacionados directamente con la pintura (Bashkirtseff, 1923; Echevarría Pereda, 1995: 131-132).

C.M. ${ }^{14}$ recopila numerosos párrafos escritos por la propia pintora que nos dan una idea de cómo debió ser su carrera artística. Por tanto, a través de la Biografía Artística de Anselma que lleva a cabo C.M. no solo descubrimos cuáles fueron sus obras y las fechas en las que fueron realizadas; sino también, tenemos la oportunidad de conocer las impresiones de la artista desde sus propias palabras. Éste es uno de los puntos fundamentales para cualquier estudio de los artistas; y más aún, de las pintoras, puesto que son escasos sus testimonios. Alejandrina de Gessler y Shaw era, ante todo, pintora; pero siempre tuvo la costumbre de escribir sus experiencias pictóricas y vitales.

Fulana de Tal destacará por la sencillez con la que escribe sus memorias y la predilección por esa intrahistoria de la que nos hablaba Miguel de Unamuno (Unamuno, 1996). Es importante detenernos en este punto, puesto que la fecha en la que se publican sus Recuerdos es 1899 y emplea el concepto «modernista», coincidiendo con el denominado «problema de España», tras la pérdida de Cuba y Filipinas en el Tratado de París del 10 de diciembre de 1898, el Desastre del 98; cuando escritores y escritoras sientan un gran descontento con la situación cultural, económica y política por la que atraviesa el país. El Modernismo ${ }^{15}$, que congregará numerosas tendencias, intentará dar respuesta y a ese inconformismo y frustración intelectual. No obstante, en aquella época, «modernista» era considerado aquél o aquélla que propusiese novedades y cambios que contribuyeran a la modernización de la sociedad.

Por las palabras de la pintora, deducimos que pudo haber estado pendiente al pensamiento de Unamuno que, en su día entrecruzó cartas con Gavinet sobre la situación política española y que fueron recogidas en El porvenir de España, y que consideró la vida de todas aquellas personas anónimas y humildes «la sustancia del progreso, la verdadera tradición» de los pueblos. En

\footnotetext{
${ }^{14}$ Nuestras investigaciones nos han llevado a deducir que las siglas C.M. responden a Crista Morphy, la hija del primo de la pintora, el Conde de Morphy, presidente de la sección de Música del Ateneo de Madrid.

${ }^{15}$ En relación a ese concepto y su relación con el género, conviene señalar la obra de Susan Kirkpatrick sobre Mujer, modernismo y vanguardia en España (1898-1931), donde se apunta la clasificación de la literatura española de entresiglos en dos tendencias opuestas: modernismo, vinculado a lo femenino; y 98, codificado como masculino (Kirkpatrick, 2003: 10). También cabe mencionar la definición de modernización que realiza Rita Felski como «proceso de desarrollo socioeconómico que conlleva innovaciones científicas y tecnológicas, industrialización y un mercado capitalista en expansión, mientras que el modernismo es una respuesta estética a dichos cambios y la modernidad una etiqueta totalizadora para un período histórico y una visión del mundo definidos por oposición a la tradición y el pasado» (Kirkpatrick, 2003: 12).
} 
nuestra opinión, la De Gessler-Shaw habría podido basarse en esta concepción de la vida y es, por ello, que dedica sus Recuerdos de Cádiz y Puerto Real a describir la vida cotidiana de anónimos/as gaditanos/as; huyendo de aquéllos o aquéllas que pretendían darse importancia. Creemos que la pintora, podría haber estado de acuerdo con la idea de Unamuno sobre el problema de España. Miguel de Unamuno explicaba que

España está por descubrir, y sólo la descubrirán españoles europeizados. Se ignora el paisaje, y la vida toda de nuestro pueblo. Se ignora hasta la existencia de una literatura plebeya, y nadie para su atención en las coplas de los ciegos, en los pliegos de cordel [...]. Tenemos que europeizarnos y chapuzarnos en el pueblo. El pueblo, el hondo pueblo, el que vive bajo la historia, es la masa común a todas las castas [...] (Unamuno, 1996: 153-170).

La pintora era una verdadera española europeizada, que prestaba atención al pueblo, como puede verse en sus Recuerdos; e incluso, llegó a rescatar esa literatura plebeya ${ }^{16}$ que era ignorada, según el filósofo, por la sociedad de la época.

Además, la abundancia de episodios religiosos relacionados con la vida de las mujeres gaditanas podrían estar apoyando el pensamiento de Unamuno: «La mujer es la base de la tradición en las sociedades... A las mujeres se debe acaso la conservación de la fe, ellas mantienen con su silencio la tradición de la piedad» (Unamuno, 1996; Kirkpatrick, 2003: 32).

¿Podría la pintora haber dado una respuesta al problema de España? Si Emilia Pardo Bazán escribía «europeicémonos» como solución a la crisis por la que atravesaba nuestro país, pretendía que España fijase su atención en los países europeos; Alejandrina de Gessler y Shaw propuso mirar hacia el pasado, hacia las costumbres ${ }^{17}$ y alejarse de una sociedad que habría perdido el verdadero sentido de la vida.

Quizás Alejandrina de Gessler y Shaw no gustaba de los actos sociales y refinados del París de su época, representaciones teatrales y salones organizados por mujeres de clase alta, como el célebre salón de la pintora y alumna de Charles Chaplin, Madelene Lemaire; alejados de la espontaneidad del pueblo. Prefería sus estancias en el campo junto a sus familiares, disfrutando de la naturaleza; o anhelaba la llaneza y la candidez del teatro gaditano de títeres de la Tía Norica.

No siempre París deslumbraba a las jóvenes pintoras y dejaba un sentimiento sobrecogedor como el que causó en Emilia Pardo Bazán: «Si yo no cono-

${ }^{16}$ Véase el Capítulo II, el apartado «Anselma, ¿pintora perteneciente a la escuela gaditana?», donde se aborda cómo la pintora recordaba con nostalgia los cantos de un anciano ciego en la puerta de su casa.

${ }^{17}$ Cabe mencionar el caso de la escritora Cecilia Böhl de Faber, que escribía bajo el pseudónimo de Fernán Caballero, se preocuparía de recoger en La Gaviota la vida cotidiana del pueblo español, para mostrar sus virtudes frente al extranjero. Vid. Isabel Álvarez (1994: 353). 
ciese bastante la gran capital de Francia, ¡qué emoción experimentaría al encontrarme, como quien dice, puesto el pie en el estribo para salir hacia ella [...]» (Pardo Bazán, 1899: 27). Resulta paradójico que habiendo vivido en un París tan dinámico e influyente, la pintora mirase hacia la pequeña y alegre Cádiz. Su autobiografía invita a pensar si la pintora, en el caso de no haber contraído matrimonio con el diplomático francés Charles Lacroix, habría permanecido toda su vida en su tierra natal. Aquí conviene resaltar la vida de la pintora y escritora española Leopolda Gassó y Vidal (1848-1885) (Díaz Sánchez, 2012: 440 y 443) quien, habiendo tenido la oportunidad de viajar a París, prefirió quedarse en Toledo, por ser ésta una ciudad que le aportaba mejores sensaciones en su formación artística; o la pintora Antonia Bañuelos Thorndike (1879-1920) (Diego, 2009: 377) que, según los que la conocían, prefería estar en su estudio antes que participar de las muchas actividades de ocio que podía disfrutar en París. ¿Habría tenido algo que ver el hecho de que Gassó y Vidal permaneció soltera durante toda su vida y por consiguiente, pudo elegir libremente la ciudad donde quería vivir?

Con respecto a esta cuestión, habría que tener en cuenta la crítica feminista y cómo considera que el matrimonio supondría para la mujer una «muerte civil» dado que «la mujer casada no estaba autorizada a controlar sus ingresos, ni a elegir su domicilio, ni a administrar los bienes que le pertenecían legalmente, ni a firmar documentos, ni a prestar testimonio» (Amorós y Miguel, 2007: 266).

Cierto es que su marido Charles Lacroix, siempre se preocupó de organizar viajes a Cádiz, por expreso deseo de la pintora. Uno de las visitas claves a Cádiz, que repercutió en su pintura costumbrista, fue la realizada con su marido, tras su matrimonio, en 1871.

\section{LA INFLUENCIA DEL GÉNERO COSTUMBRISTA EN LA OBRA LITERARIA DE ANSELMA}

No cuento, como se verá, meterme en hablar, ni con mucho, de todos los usos y costumbres de mi tiempo; hágolo sólo de algunos cosas sobre las que aunque muy sabidas, me ha sido especialmente grato el extenderme y machacar; sólo me he ocupado y me ocuparé en las que, aunque insignificantes en su forma, acaricio como retrospectivas ilusiones personales. A imitación del poeta diré que estas familiarísimas relaciones son para mí hojas desprendidas del árbol del corazón, que por eso con cariño recojo, y nada más. (Fulana de Tal, 1899: 69).

El poeta al que se refiere Alejandrina de Gessler y Shaw es el escritor español José de Espronceda (1802-1842). Su fallecimiento coincide prácticamente con la fecha que la pintora elige para empezar a exponer sus Recuerdos de Cádiz y Puerto Real. Esto es, 1841, cuando contaba con diez años. La elección de dicho verso estaría relacionada con la inclinación de la artista por la corriente romántica en la España del siglo XIX que había irrumpido con 
fuerza en todos los ámbitos de la cultura, especialmente en la literatura y en la pintura. Los versos están extraídos de uno de los poemas más emblemáticos del poeta español: El estudiante de Salamanca. El escritor se convirtió en un auténtico prototipo de poeta romántico dado su participación en las barricadas revolucionarias francesas y en la política española como diputado.

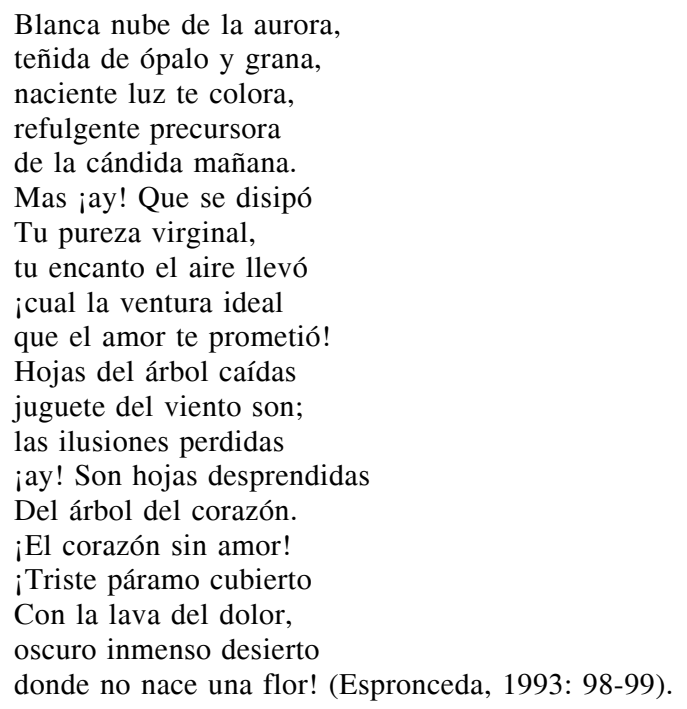

Estos escritos se enmarcan dentro del género costumbrista ya que «revela aquellos aspectos de la realidad que escapan a la historia. Estudia y describe al pueblo, y el cambio surgido durante la transición del Antiguo Régimen a la sociedad urbana moderna» (Rico, 1982: 338). Precisamente los aspectos recogidos en la definición que efectúa Francisco Rico se hallan en las declaraciones de la pintora a lo largo de sus Recuerdos. Podríamos extraer tres líneas fundamentales que caracterizarían el género costumbrista y que se aprecian en la obra literaria de Alejandrina de Gessler y Shaw:

- Revela aquellos aspectos de la realidad que escapan a la historia:

$\mathrm{Al}$ estudiar la historia vemos que con el tiempo se desvanecen los detalles, sobresaliendo únicamente los hechos importantes que sólo entonces toman la significación que les corresponde, de la que carecían en la época en que acaecieron. [...]. Otro tanto sucede en la vida de cada cual; muchas de las cosas que parecen insignificantes cuando pasan suelen revelarse luego como dignas de interés, no habiéndole parecido cuando estaban demasiado cerca (C.M., 1908: 3).

- Estudia y describe al pueblo:

Segura estoy de que hoy día habrán desaparecido muchas de las sencillas costumbres de aquellos tiempos, que ya nos parecían anticuadas o antiguachas, como en 
Cádiz decíamos; pero es verdad que eso mismo les da cierto mérito y voy a recordar algunas; primero, por el gusto de rejuvenecerme al hablar de ellas, y luego porque, como Antiquum documentum, son curiosas de anotar por su sabor a reliquia (C.M., 1908: 2-3).

- El cambio surgido durante la transición del Antiguo Régimen a la sociedad urbana moderna.

Sirvieran para demostrar la llaneza e ingenuidad con las que tanto los niños como la gente grande se divertían entonces, lo que va desapareciendo en la actualidad, gracias a las exigencias del exagerado lujo y a la esclavitud de querer siempre aparentar y darse importancia (C.M., 1908: 3).

En estos tres párrafos se entremezclan algunos de los principales rasgos del Romanticismo. En primer lugar, el «yo» como fuente y guía de la creación literaria que tiene que ver con la potenciación del individualismo y la subjetividad. Evidentemente, la pintora describe una vida cotidiana gaditana de la que ella fue partícipe directa. Por tanto, Fulana de Tal recoge sus experiencias personales y sus sensaciones. De modo que sus recuerdos son «hojas desprendidas del árbol del corazón» que «con cariño recoge» al plasmarlas por escrito. El símil que efectúa entre el motivo por el que escribe y el poema de Espronceda nos deja al descubierto el eje central del Romanticismo: el corazón y el cariño.

Anselma recurriendo a sus memorias, transfiere la mirada de lo popular a su pintura, haciendo que ésta sea enmarcada dentro de la estética costumbrista. Si bien, hay que especificar que de las dos escuelas costumbristas fundamentales del romanticismo español, la madrileña y la andaluza, Anselma se decanta por esta última dado que incidiría en un «pintoresquismo amable y folclórico, alejado de cualquier intento de crítica social» (Junquera, 2003: 69) que sí tendría en cuenta la escuela madrileña.

Dentro de esa estética costumbrista, se enmarca la descripción nostálgica de los oficios de la época que serán protagonistas de la pintura costumbrista gaditana. La pintora nos hablará de la figura del Aguador, una profesión que tomará como protagonista de uno de los cuadros que ejecutó en Cádiz.

Con su santa paciencia, llamaba en seguida Domingo al primer aguador ambulante que percibíamos de los que constantemente paseaban por las calles gritando: ¡Agua del Puerto, quién quién agua! Y acudía éste presuroso.

Estos aguadores llevaban siempre apoyado sobre fuerte pedazo de cuero, y a cuestas sobre su hombro izquierdo, un grandísimo cántaro de barro blanco con asas; la misma clase de barro que el de las frescas alcarrazas. Para sujetar el cántaro pasaba el hombre el brazo derecho sobre su cabeza, algo hacia atrás, y con la mano lo sostenía por una de sus fuertes asas.

El aguador era un oficio tan popular en la ciudad que incluso se había creado un cuento infantil en forma de poema que la pintora reproducirá y que dice así: 
Aquí me quedo algo parada, porque se me figura que se llamaba Periquillo, y, por otra parte, teniendo luego que tratar de otro Periquillo, será cosa que no se llamase así el pobre aguador. Grave cuestión que resuelvo sin titubear, no queriendo romperme la cabeza, dejándolos de tocayos. Con que adelanto:

Periquillo el aguador

Muerto lo llevan en un serón.

El serón era de paja,

Muerto lo llevan en una caja.

La caja era de pino,

Muerto lo llevan en un pepino.

El pepino era zócato,

Muerto lo llevan en un zapato, etc., etc. (Fulana de Tal, 1899: 16).

Desgraciadamente, dado que sus cuadros están en paradero desconocido no estamos al corriente de cómo proyectó Anselma sus Aguadores, si habría algún guiño velazqueño; si habría naturaleza muerta, o si veríamos reflejado un asunto picaresco tan propiamente de las obras de Miguel de Cervantes que podría haber inspirado al gran maestro español. Sí sabemos por C.M. que un cuadro bajo el título Aguador fue ejecutado en Cádiz, en 1871.

Por tanto, para entender la trayectoria artística, sobre todo, una producción pictórica resultado de ese viaje a su tierra natal, tras iniciar su formación artística, que en su mayor parte, se ha perdido y que solo conocemos a través de los títulos que recoge C.M. en la Biografía Artística de Anselma; debemos prestar atención a su autobiografía. De hecho, muchas de las obras que solo conocemos por esos títulos, gracias a sus memorias, hemos podido reconstruir su posible temática.

\section{CONCLUSIONES}

A través de los cinco apartados, queríamos abordar la autobiografía femenina desde el caso de la pintora Anselma. Hemos considerado aspectos esenciales como abordar un panorama breve sobre la autobiografía; de qué manera se empezó a vincular Anselma con Fulana de Tal; la importancia de la autobiografía de la artista por contemplar las dos etapas vitales (infancia y adolescencia) consideradas sin relevancia alguna en comparación con la etapa adulta (adultocentrismo); la estructura de sus recuerdos emulando a un relato de viajes; y finalmente, el estilo en el que se inspira dicha autobiografía, el costumbrismo.

Quisiéramos manifestar que su aportación literaria es relevante, pese a que se trata de la primera y única vez que Anselma se acerca a la literatura. En primer lugar, porque es difícil hallar autobiografías femeninas, y más aún, de mujeres artistas españolas. En segundo lugar, porque se decanta por reflejar solo una parte de su vida, aquélla que tiene menos relación con su faceta como pintora, la infancia y la juventud. Probablemente porque su principal interés 
era recordar su tierra natal, Cádiz; entonces, ¿estaría Anselma alejándose de una autobiografía, definida por Romera Castillo, como «literatura referencial del yo existencial» (Romera Castillo, 1981: 13)? Esto nos lleva a preguntarnos si la pintora se inspiró en autobiografías u otros géneros literarios para escribir sus recuerdos. Y efectivamente, pudo haberse basado más bien en el relato de viajes. Posiblemente la pintora habría leído mucho sobre cómo habrían descrito la ciudad, autores y artistas relevantes de la época, en sus relatos de viaje. Este dato nos permitiría observar cuál fue la estructura que la pintora siguió; si bien, hay que decir que sus memorias no responden a los rasgos comunes, pese a las diversas maneras de enfocar el relato de viajes, puesto que se trata de una gaditana que escribe sobre su tierra natal. De modo que no existe el característico «extrañamiento inicial ante lo desconocido» (Rubio Martín, 2011: 66).

Por otro lado, es crucial contextualizar la obra de Anselma. Sus memorias son publicadas en 1899. Se trata de un año en el que escritores y escritoras plasmarán sus impresiones sobre el momento que vive España. ¿Pretendía Anselma mostrar costumbres y actitudes que se habrían perdido en nuestro país y que habría que recuperar?, ¿influyeron los conflictos de 1898 para que la pintora volviera la mirada hacia los años felices que vivió en su país?

Por último, sus memorias suponen una fuente fundamental para el conocimiento de las costumbres y tradiciones gaditanas; así como la reconstrucción de la historia del teatro gaditano de títeres, como es la información valiosa que se desprende de su descripción del teatro de marionetas «La Tía Norica».

Pese a nuestras interpretaciones, es difícil asegurar satisfactoriamente los motivos por los que Alejandrina de Gessler y Shaw decidió no revelar su identidad, ni tan siquiera, exponer algún episodio relacionado con el ambiente artístico en su entorno familiar y en el Cádiz del siglo XIX. Sin embargo, su autobiografía se ha convertido en un documento relevante y de obligada consulta a la hora de acercarnos a la vida cotidiana del Cádiz del siglo XIX.

\section{BIBLIOGRAFÍA CITADA}

Almarcegui, Patricia (2011). «El otro y su desplazamiento en la última literatura de viaje», Revista de Literatura. LXXIII, 145, pp. 283-290.

Álvarez, Isabel (1994). «Lo transgresor, lo popular y lo castizo en la configuración del universo femenino de La Gaviota de Fernán Caballero», en Cinta Canterla (coord.), VII Encuentro de la Ilustración al Romanticismo. Cádiz, América y Europa ante la modernidad. La mujer en los siglos XVIII y XIX. Cádiz: Universidad, pp. 353-362.

Amorós, Celia y Ana de Miguel (ed.) (2007). Teoría feminista: De la Ilustración al segundo sexo, 1. Madrid: Minerva Ediciones.

Bashkirtseff, Marie (1923). Diario de su vida. Madrid: América.

C.M. (1908). Biografía artística de Anselma (1861-1905). París: Librería de Garnier Hermanos. 
Cirici Narváez, Juan Ramón y Alberto Ramos Santana (1995). Gran Teatro Falla de Cádiz. Cádiz: Ed. Colegio Oficial de Aparejadores y Arquitectos Técnicos.

Díaz Sánchez, Pilar (2012). «Leopolda Gasso y Vidal (1848-1885): Pintora y escritora», en Pilar Díaz Sánchez; Gloria Franco Rubio; y María Jesús Fuente Pérez, Impulsando la historia desde la historia de las mujeres. La estela de Cristina Segura. Huelva: Ed. Universidad de Huelva, pp. 439-448.

Diego, Estrella de (2009). La mujer y la pintura del XIX español. Cuatrocientas olvidadas y algunas más. Madrid: Cátedra. Primera edición de 1987.

Doré, Gustavo y Charles Davillier (1982). Viaje por España. Madrid: Grech. Primera edición de 1879.

Durán López, Fernando (1994). «La autobiografía romántica de Gertrudis Gómez de Avellaneda y la literatura de confesión en España», en Cinta Canterla (coord.), VII Encuentro de la Ilustración al Romanticismo. Cádiz, América y Europa ante la modernidad. La mujer en los siglos XVIII y XIX. Cádiz: Universidad, pp. 459-468.

Durán López, Fernando (2001). «Las memorias de un setentón de Mesonero Romanos en el marco de la autobiografía española decimonónica», en Anales de Literatura Española, núm. 14, pp. 41-83.

Durán López, Fernando (2002). «La autobiografía como fuente histórica: problemas teóricos y metodológicos», en Memoria y Civilización. 5, pp. 153-187.

Echevarría Pereda, Elena (1995). Andalucía y las viajeras francesas en el siglo XIX. Málaga: Universidad.

Espronceda, José de (1993). El Estudiante de Salamanca. El Diablo mundo. Madrid: Castalia.

Fulana de Tal (1899). Recuerdos de Cádiz y Puerto Real. París: Librería Garnier.

Junquera, Juan José (dir.) (2003). Historia Universal del Arte. Del Romanticismo al Modernismo. Madrid: Espasa.

Kirkpatrick, Susan (1991). Las Románticas. Escritoras y subjetividad en España 1835-1850. Madrid: Cátedra.

Kirkpatrick, Susan (2003). Mujer, modernismo y vanguardia en España (1898-1931). Madrid: Cátedra.

Pardo Bazán, Emilia (1899). Obras Completas, XIX. Al pie de la Torre Eiffel. Madrid: Est. Tip. de Idamor Moreno.

Ramírez Goicoechea, Eugenia (2009). Evolución, Cultura y Complejidad. La humanidad que se hace a sí misma. Madrid: Ed. Universitaria Ramón Areces.

Ramos Santana, Alberto (1992). Cádiz en el siglo XIX. De ciudad soberana a capital de provincia, III. Madrid: Sílex.

Rico, Francisco (1982). Teoría y crítica de la literatura española. Romanticismo y Realismo. Madrid: Crítica.

Romera Castillo, José Nicolás (1981). «La literatura, signo autobiográfico (El escritor signo referencial de su escritura)», en José Nicolás Romera Castillo (coord.), La literatura como signo. Madrid: Playor, pp. 13-56.

Romero Ferrer, Alberto y Fernando Durán López (ed.) (2001). Veinticinco escritores gaditanos raros y olvidados. Cádiz: Diputación.

Rousseau, Jean-Jacques (2002). Emilio. Barcelona: RBA. Primera edición de 1762.

Rubio Martín, María (2011). «En los límites del libro de viajes: seducción, canonicidad y transgresión de un género», Revista de Literatura. LXXIII, 145, pp. 65-90.

Seguí, Virginia (2003): «Análisis de la tipología femenina a través del género costumbrista», en María José de la Pascua Sánchez y Gloria Espigado Tocino: Frasquita Larrea y Aherán. Europeas y españolas entre la Ilustración y el Romanticismo (1750-1850). Cádiz: Universidad, pp. 267-285.

Solís, Ramón (2000). El Cádiz de las Cortes. La vida en la ciudad en los años de 1810 a 1813. Madrid: Sílex. 
Soriano Nieto, Nieves (2009). Viajeros románticos a Oriente: Delacroix, Flaubert, Nerval. Murcia: Universidad.

Unamuno, Miguel de (1996). En torno al casticismo. Madrid: Biblioteca Nueva. Primera edición de 1895.

Vigée Lebrun, Elisabeth (1903). Memoirs of Madame Vigée Lebrun. New York: Doubleday, Page \& Company.

Fecha de recepción: 15 de junio de 2014.

Fecha de aceptación: 16 de diciembre de 2014. 